\title{
Editorial
}

\section{Exposição da sinceridade}

A "chamada" reproduzida nesse dossiê tinha uma ambição: suscitar um tipo de texto pouco usual em nosso meio, a saber, o testemunho de artistas, críticos, historiadores e filósofos da arte sobre o que as/os motiva na sua atividade de pesquisa, produção, publicação, exposição etc. Pergunta simples, mas que gerou algumas resistências - aqueles que renunciaram a escrever - e, felizmente, a adesão entusiasta dos outros ${ }^{1}$. Em nosso meio, não rara a existência de textos em que o artista declara suas intenções ou comunica suas reflexões acerca do próprio trabalho. Mas, quando se trata do crítico, a análise de uma obra ou o texto de um catálogo costumam ser mais distanciados. O historiador e o filósofo parecem ainda mais "escondidos" atrás de seu objeto.

O dossiê intenta misturar essas posições discursivas. Dionisíaco, Paulo Herkenhoff apresenta em Quarentena blues as várias facetas de sua paixão artística e cultural. Num grito vulcânico de desespero pandêmico e de amor pelas obras que constituem sua coleção interior, o texto é incendiário: bate, provoca, salta, esbarra, insiste, gira sem fim, verdadeiro poema rítmico-político jorrado. $O$ gabinete dos encantos e dos desencantos não nos deixa ileso. Agradecemos por essa escrita excepcional! Num outro polo, apolíneo, o filósofo e alpinista Pierre-Henry Frangne (re)constrói metodicamente os caminhos conceituais e existenciais da sabedoria que ele procura mediante a exploração criativa dos textos de filosofia (da arte), sua prática da alta montanha como forma de auto-conhecimento - estética integral - e o confronto com a morte na literatura e na (própria) vida. Ambos testemunham como o horizonte da morte subjaz nossas escolhas estéticas mais fundamentais. Mostram, em escritas aparentemente antitéticas, como circula no cosmos de cada um de nós imagens, modelos, referências, mananciais a tecer a nossa subjetividade. Espíritos, corações a nu e corpos autobiográficos inseridos no mundo da arte: tal é o leque de realidades que todo texto movimenta num equilíbrio entre o balanço metódico e a dimensão labiríntica da experiência.

Qual seria o verbo mais adequado para qualificar o exercício? Talvez aquele que Emerson Dionísio propõe. Historiador da arte, entendida nos seus modos de circulação e existência institucional, Emerson escolhe a tutela de um conceito porto-riquenho tão movediço quanto a antropofagia: bregar. De que se trata? O leitor lerá. Instigante. Parece uma dança epistemológica, alguma andança em que todo o sistema das artes é movimentado, questionado, sem que se saiba bem aonde chegar porque a circulação e articulação dos conceitos se encontra na fase do redesenho

1 O texto da chamada é reproduzido aqui após o editorial. 
das funções e das significações (bregar não rima com chegar; rima mais com caminhar). Esse verbo, estranho logos da história, da crítica e da arte, funciona como o curinga do jogo ou algum cursor que permite imprimir no espírito o desafio que toda posição de discurso e de produção em arte encarna. Outra categoria adequada seria a de sbaraglino, esse jogo veneziano lembrado por Patricia Franca-Huchet, que seria "um exemplo de combinação de paixão e tensão emocional". Essa fórmula resume a tonalidade de cada texto.

Numa oscilação entre os aspectos privado e profissional da vida, sempre a nos propor a intensidade de suas poéticas, os artistas potencializam e atualizam diálogos muito motivadores com a própria trajetória e a cena artística de hoje ou de ontem. A chama é forte. Ela se alimenta da matéria existencial e do ar das ideias. Seus textos são caracterizados por montagens discursivas e conceituais densas. É bonito encontrar a figura do artista-pesquisador, nunca assentado em certezas, como aquelas que Ricardo Maurício Gonzaga evoca no seu trabalho "...sobre o coração selvagem da arte". Qual o sentido de ser artista: para quem, por quê, com que arte?, pergunta Ricardo num texto que propõe, como o do Emerson, uma forma de ritmo sem pausa. Sua leitura nos ensina que existem artistas cuja especialidade é a máscara e outros que se abrem numa autenticidade que toca, com vibrações teóricas que fazem o mundo ressoar. Se a vida se torna uma verdadeira estética, ela também constitui um emblema da integração mútua entre imagem(-de-si) e imagens dos outros. Tudo isso poderia se somar na ideia do artista-iconógrafo - e iconófilo -, exemplificada tanto por Patricia Franca-Huchet quanto por Leila Danziger, mas também pela figura do historiador da arte. No final das contas, o que reúne os participantes, não seria a Imagem?

Explorando a dinâmica temporal das imagens, Patricia procede ao redesenho de cenas clássicas ou de cenas marcantes da própria vida num processo de "migração" espaço-temporal em que a memória adquire novas perspectivas. Seu texto aprofunda a dupla questão da "nãocontemporaneidade" iconográfica no desenho e de outra, que enfrentamos todos: a "reiniciação" das imagens. Fica claro, em todas as escritas, que nossos trabalhos experimentam de maneira constitutiva e fenomenológica "uma pluralidade de tempos". A diferença do artista é que essa múltipla temporalidade gera sempre alguma visualidade, alguma iconicidade. A poética também autobiográfica de Leila Danziger enuncia outra motivação, compartilhada com o historiador ou o filósofo: "habitar o visível como uma exigência". O que Leila enfrenta são os modos de ser - históricos, tradicionais, scripturais, icônicos - da perda, do exílio, da morte, da genealogia, tantas intensidades... Leila desenha um mapa crítico jamais solúvel numa síntese. Isso caracteriza também o diálogo de Bárbara Mol e Rachel Falcão: os "asteriscos" alternativos do diálogo preenchem um platô interativo tão veloz e amplo que ele parece pôr a paixão artística "à beira" da implosão.

Os historiadores da arte trabalham sobre as imagens, mas raramente dizem por que, ou não afirmam nitidamente sua força de mobilização quase íntima. A chamada conseguiu quebrar o gelo: o que move o olhar do historiador, Laurent Bove, Sandra Makowiecky e Luana Wedekin, por exemplo, o dizem: cada um com seu museu imaginário ou suas viagens in loco. In loco e nos livros: as fontes de toda história, num 
gesto de empatia que movimenta nossas coleções interiores. Quais imagens nos habitam? Não é uma pergunta irrisória. É ela que tece tudo. Um crítico de arte dizia um dia que sua coleção se resumia ao Ulisses de James Joyce e às Variações Goldberg de Bach interpretadas por Glenn Gould. A coleção que eu habito no meu interior é uma força de disparo. Todos nós possuímos uma. Agradecemos quem, aqui, nesse dossiê, aceitou dividi-la. Essa origem da motivação cria uma clara isonomia entre a posição do historiador e a do artista: ambos inseridos na circulação das imagens e no seu lançamento público. Um livro de história da arte é uma forma de curadoria. O historiador pode (re)expor as imagens através de um processo de reiteração. $O$ historiador faz reemergir. É a conversa de Sandra Makowiecky "no sofá com Huizinga", um discurso eletrizado pela empatia com a pintura, que muitos não sabem mais olhar e entender. A história da arte se torna lugar de expansão e exposição do prazer, notadamente o prazer do detalhe, uma certa "obsessão do olhar", condição de um trabalho na história e na análise das imagens. Ao ler o texto de Luana Wedekin, podemos nos perguntar, já que Pulcinella sobrevive à sua própria morte, se sua figura não seria o emblema potente de todo historiador: Pulcinella alegoriza a sobrevivência e a persistência supratemporal. Ele poderia bem significar que toda história da arte, como sugere o título, adquire sua plena significação se for compreendida "no balanço de Pulcinella": fala do caráter produtivo do anacrônico que permanece no tempo e que desafia nossa interpretação. Ida e voltas entre tempos. O questionamento se prolonga: quem já intuiu a força política das pinturas aparentemente conhecidas de Peter Bruegel no século XVI, como o filósofo Laurent Bove as redescobre, ao propor uma leitura em chave espinozista das mensagens de libertação política no contexto da luta dos Países-Baixos contra o domínio teológico-político espanhol? Bove tem um olhar que "reinicia" Bruegel, que o reinventa, apresentando a tese de um Bruegel como artista-do-comum. Contribuição à genealogia de uma questão artística atual. Esse texto é uma afirmação instigante sobre as motivações epistemológicas de um filósofo da arte querendo aproveitar um estudo - aqui, remetemos ao livro de cujo artigo aborda apenas uma parte - inovador sobre um imenso artista do outrora. Seu modo de fazer constitui um modelo metodológico.

Ouvimos falar frequentemente de ressignificação. Tudo aqui vai nessa direção: a ressignificação exige um movimento intenso nas fontes. No plano da movimentação das fontes, não há como dizer que o artista, o historiador ou o filósofo ajam de maneira diferenciada.

Nesse sentido, nada mais significativa que a problemática aberta por Marina Romagnoli Bethonico. "Fazer mundos, fabricar possíveis" constitui um avesso brilhante do espelho. Vestindo a fundamental motivação artística - fazer imagens - com um vocabulário teórico renovador que circula na fotografia ou no campo pós-fotográfico, Marina problematiza a mudança de paradigmas entre a lógica analógica e as imagens que a lógica ficcional das imagens pós-verdadeiras. Certos aspectos da discussão contribuem a re-situar os desafios críticos de toda imagem e instauram um diálogo potencial com o resto do dossiê, a invenção de mundos possíveis sendo um elemento nuclear do sentido que todo artista projeta e da significação que todo historiador ou filósofo enuncia, seja no viés analítico, seja no viés metafísico. 
Estranha como o que parece normal na arte constitua um desafio para a arquitetura. É o que Diogo Carvalho sugere através da ideia de tornar imperativo "a educação estética e o descobrir-se sensível" do arquiteto. A argumentação é imparável: a arquitetura só se salva se conseguir alcançar um patamar de exigência que resulta, no caso, de uma batalha: adquirir, e, depois, casar o sensível e o espiritual. A proposição, no campo da arquitetura, é audaciosa. Mas não há outra que preste. Não há jogo possível. O que seria análogo ao exercício da liberdade artística em inventar mundos esbarra na demanda social e nas limitações do material. A norma, do lado da arte, se torna, aqui, utopia. Ninguém melhor colocado que Giuseppe Penone para emblematizar esse balanceamento integral do sensível e do espiritual. Os textos que Marina Câmara Dayrell nos apresenta constituem o primor de sua tradução em curso dos escritos do artista ${ }^{2}$. Penone pode ser eleito a figura tutelar do conjunto: a findá-lo; a abri-lo. O desenho da capa é uma bela alegoria: o que uma foglia que semelha ser um cérebro contém de inervações. A escrita de Penone advém para fazer eco a tudo o que lemos. Nas fibras da mimesis, reencontramos as falésias do alpinista, já que ambas a verticalidade mineral e a planaridade da impressão falam de natureza e do conhecimento, em todas suas facetas. Não poderíamos imaginar conclusão mais apropriada. Nesse sentido, a estética, mais uma vez, chegou na ética. Como deve.

Stéphane Huchet (PPGArtes/UFMG)

\section{Autorretratos críticos: o que me/nos/vos motiva?}

Esse dossiê é um teste. $O$ que pensamos realmente da nossa própria atuação seja como historiador, seja como crítico, seja como artista?

O trabalho de um artista, de um crítico ou de um historiador acontece numa estrutura tão simples quanto um " $X$ ": existem, para os vários lugares que têm a arte como sua matriz de realização, relações estreitas e encontros que a letra " $X$ " sintetiza perfeitamente. $O$ que encontramos de instigante nela é a circulação nas suas linhas. Apresentam possibilidades mais lineares ou de bifurcação para várias figuras profissionais que se deslocam e convergem para criar, criticar, historicizar; produzir obras e conhecimentos; inventar narrativas e (re)criar sentido etc. Mas o mais importante é que a circulação no " $X$ " se determina com relação ao ponto de cruzamento das linhas. Se o historiador, o crítico, o filósofo, o antropólogo, o sociólogo, o curador etc. traçam as linearidades, é porque eles estão em contato constante com o centro do desenho, núcleo propulsor. Se a esse centro tudo vai; se dele tudo vem, é porque ele tem uma identidade universal: é o artista, com suas obras, suas imagens.

Mas o que significa: "o que me/nos/vos motiva?" A resposta deveria dizer respeito à relação que instituimos com a arte, seus desafios, suas perspectivas, sua significação, sua complexidade, seus impactos na realidade; ela poderia também interessar o vínculo que podemos instituir com sua história, a saber, o que os artistas fazem hoje e fizeram no passado, o legado artístico que todos nós herdamos. E sabemos o quanto rico, denso e infinito ele é!

O dossiê propõe, portanto, a elaboração de uma série de autorretratos críticos 
capazes de apresentar para o leitor as motivações que sustentam o que cada um de nós faz quando enxerga a arte, seja contemporânea, moderna, clássica, antiga, indígena, religiosa, política, social, popular, brasileira ou não etc. O que interessa no que a arte é, faz e pode fazer hoje, o que a arte foi e fez ontem? O que desperta meu interesse e meu desejo? Por que sou historiador da paisagem romântica? Por que sou performer e não pintor, ou os dois juntos? Por que focalizo toda minha energia criativa ou investigativa num mesmo tipo de objeto ou preocupação (é bem assim que vemos artistas ou pesquisadores explorando o mesmo campo estético anos a fio, ou outros sentindo a necessidade de mudar regularmente)? Por que trabalho sobre a arte de tal ou tal lugar, de tal ou tal momento, de tal ou tal cultura, procedendo assim a recortes espaço-temporais ou estético-culturais estrategicamente determinados? Por que só a arte atual se salva a meus olhos? Por que só as causas políticas consideradas urgentes me parecem dignas de ser exploradas e por que penso que a arte deveria estar a serviço de causas? Por que me defino em função de modelos artísticos ou epistemológicos que contribuíram a determinar minha personalidade ou me recuso a reconhecer predecessores? "Por que?" infindável e perguntas aparentemente ingênuas, mas que abrem a Caixa de Pandora dos estratos mais complexos da minha maneira de me situar na cena (trans-; multi-; inter-; uni-) disciplinar que me diz respeito como produtor de significações artísticas e críticas. Se, como analisou Panofksy, a Caixa de Pandora é a caixa dos múltiplos dons que determinam a gama de riquezas e fenômenos presentes na vida, porque não pensar que nosso trabalho seria mais uma maneira de contribuir simbolicamente à fascinante complexidade do mundo?

Isso tudo requer paixão. Ah! A psicologia de baixo escalão está de volta! Não. Quando falamos em paixão, não remetemos ao sentimento pessoal, mas a algo mais potente: o páthos que me anima como pesquisador, artista(-pesquisador), historiador-crítico, esteta, curador. O páthos como fonte genésica e genérica. Afeto, se quisermos, mas no sentido de uma paixão inventiva, crítica, epistemológica. Trata-se de nossa disposição, do dispositivo que construímos pacientemente ao longo dos anos para amparar e consolidar nossa atividade. Trata-se de uma disposição e dos dispositivos interiores e profissionais que determinam o tom e o perfil de nossa relação com a arte, sua história, sua dinâmica; as obras, as imagens, os movimentos; as ousadias, as estagnações, as experimentações; as categorias teóricas; os ciclos, os modelos; as antecipações, as premonições, essa competência "sísmica" do artista em registrar e manifestar nas obras as forças profundas do mundo, como dizia o crítico de arte russo Nicolaï Punin há cem anos. O que me/nos/vos motiva? Tal é a pergunta endereçada às pessoas, aos agentes, às personagens - todos nós - que se cruzam um dia no $X$ da questão.

É evidente que a resposta não pode acontecer sem solicitar uma certa visão do tempo: além do meu tempo sensitivo e espiritual, o tempo da arte. $O$ dossiê tenta aproveitar o autorretrato crítico para criar uma constelação significativa em que os ensaios pensam o corolário de todo reflexão sobre a arte e sua dinâmica intrínseca: a relação com o tempo, nosso, de ontem. Ele é o componente primordial da difícil dialética que cada artista, mas também todo profissional mais distanciado, precisa 
trabalhar para estruturar sua fala. Essa inserção pode gerar paradoxos estimulantes. Trata-se sempre de superposições, de camadas mistas, de fluxos plurais: é o cineasta Peter Greenaway que faz de seu filme Ronda Noturna um eco a Rembrandt, que teria inventado o cinema; é o ambiente de Hélio Oiticica que integra, entre outros agentes, o aporte considerável da fenomenologia; é Glauber Rocha que reata com todas as potências da alegorização; é André Malraux que evoca no seu Museu Imaginário a contemporaneidade de Skakespeare, Beethoven e Rembrandt; é Jannis Kounellis que chama sua coleção ideal de referências heterotemporais de "pantheon"; é Didi- Huberman que identifica nas camadas do tempo seus parceiros de pensamento e que os transforma em figuras de inteligência da história; é o cenário estupendo que Yadegar Asisi monta no Pergamon de Berlim, a recriar, usando todos os recursos da tecnologia digital, reatando com o modelo romântico do panorama, as vinte-e-quatro horas de um dia na cidade helenística de Pérgamo; é o polêmico Vik Muniz que encena a iconografia clássica em ações performáticas que mesclam pobreza social e teatro da glória, etc. Tais funcionam os mecanismos polissêmicos de montagem e assemblagens em nosso museu interior. Ninguém escapa a essa regra. Podemos não ser benjaminianos, mas o agora e o outrora não cessam de se encontrar...

Repitamo-lo: nenhum de nós se relaciona com ou se insere na cena artística e epistemológica sem possuir ao seu redor e no seu mais íntimo uma matriz generativa tendo função de propulsor. A canalizamos. Criamos e balizamos percursos a partir de um saber transmitido, de conceitos e conhecimentos acumulados, mas vivos, submetidos a revisões, a perspectivas de todo tipo que convocam o que Baudelaire chamava de "ordens do espírito"... Podemos ignorá-las, mas estão pairando no ar que respiramos.

Esses parcos exemplos, bem clássicos, sugerem o quanto insuspeitos são os processos que determinam, na articulação da sensibilidade e da razão, nossas montagens. Nesse círculo mágico, oscilamos entre lucidez e errâncias de todo tipo. Por que não reconhecer, eventualmente, que tateamos frequentemente e que a condição labiríntica dos processos pode constituir nossa estética favorita?

Percorrendo, portanto, o "X" que nos simboliza, navegantes do mesmo barco, movidos pelas diversas velocidades dos ventos e sempre a renovar a cornucópia da invenção, podemos aqui, em plena liberdade, privilegiar as mais diversas ordens do tempo, sempre responsáveis pelas lutas políticas inerentes ao nosso campo e pela salvação crítico-contemplativa das heranças históricas. 